\title{
ANALISIS PERBANDINGAN ANTARA RESPON SEISMIK SINTETIK PP DAN PS BERDASARKAN PEMODELAN SUBSTITUSI FLUIDA PADA SUMUR
}

\author{
Nova Linzai, Firman Syaifuddin, Amin Widodo \\ Jurusan Teknik Geofisika, FTSP Institut Teknologi Sepuluh Nopember \\ e-mail: nova.linzai@gmail.com
}

\begin{abstract}
Abstrak. Penelitian yang bertujuan untuk menganalisa perbandingan sintetik PP dan PS berdasarkan pemodelan sumur. Penelitian ini mencakup pemodelan data sumur dan pembuatan seismik sintetik gather PP dan PS. Pemodelan data sumur yang dilakukan adalah pemodelan substitusi fluida ( $100 \%$ air, minyak dan gas) dengan teori Gassman dan proses editing log. Pembuatan seismik sintetik gather PP dan PS berdasarkan prinsip gelombang elastik dengan memanfaatkan komponen vertikal dan horizontal. Pemodelan sintetik ke depan menggunakan prinsip ray tracing dengan jumlah offset 101 dengan range offset $0-4000 \mathrm{~m}$. Penelitian ini menunjukkan bahwa hasil dari substitusi fluida sangat mempengaruhi kecepatan gelombang $\mathrm{P}$ dan densitas, sedangkan perubahan terhadap kecepatan gelombang $\mathrm{S}$ tidak terlalu signifikan. Reservoir merupakan sand gas sehingga nilai kecepatan gelombang $\mathrm{P}$ ketika disubstitusi gas lebih besar daripada minyak. Hasil dari sintetik gather PP dan PS adalah perbedaan time position. Efek substitusi fluida (fluida pengisi pori batuan) terhadap respon seismik berupa time delay (efek gas) akibat adanya penurunan kecepatan gelombang $P$.
\end{abstract}

Kata Kunci: substitusi fluida; sintetik gather PS; gelombang elastik; time position

\begin{abstract}
The objective of this study is to analyze the seismic modeling response in PP and PS synthetic gather based on well fluid substitution modeling. The methodology consists of well based modeling and seismic synthetic gather PP and PS generation. Well based modeling was performed in gas, oil and brine case by using Gassman fluid substitution seismic modeling and log editing. Seismic synthetic gather PP and PS generation use the elastic wave theory with the consideration of horizontal and vertical component. The synthetic forward modeling using ray tracing with number of offset 101 and offset range $0-4000 \mathrm{~m}$. The result of fluid substitution modeling is slightly affecting the changing in compressional wave velocity and density and not significantly changing the shear wave velocity. The reservoir estimated to be gas sand, which is affect the compressional velocities for gas sand are faster than oil in the same sand. The time position differences observed between synthetic gather PP and PS. Pore fluid filling affect the seismic response in time delay (gas effect) because of the decreasing compressional velocity.
\end{abstract}

Keywords: fluid substitution; synthetic gather PS; elastic wave; time position

\section{PENDAHULUAN}

Dalam survey eksplorasi seismik ada dua jenis gelombang yang dapat dimanfaatkan yaitu gelombang $\mathrm{P}$ dan $\mathrm{S}$. Setiap gelombang diharapkan dapat membantu dan mempermudah eksplorasi minyak dan gas. Survey seismik eksplorasi konvensional banyak memanfaatkan Gelombang PP. Gelombang PP merupakan metode seismik eksplorasi yang menggunakan energi gelombang $P$ menjalar ke bawah dan direfleksikan ke atas sebagai gelombang $\mathrm{P}$ juga. Adapun kekurangan dari gelombang $\mathrm{PP}$ adalah energi gelombang $\mathrm{P}$ akan tersebar (dispersi) dan teredam (atenuasi) ketika melewati daerah tersaturasi gas. Keberadaan Gas pada reservoir dapat menghasilkan efek kantong gas (gas chimney atau gas masking) yang akan mengurangi kualitas gambar penampang seismik lapisan di bawah kantong atau reservoir gas. Berbeda dengan gelombang $S$, gelombang $S$ tidak sensitif terhadap saturasi batuan sehingga dapat menembus sedimen yang tersaturasi gas. (Stewart \& Lawton, 1996)

Sehingga para ahli geofisika yang selama ini hanya memanfaatkan gelombang $\mathrm{P}$ pada eksplorasi seismik, menemukan cara baru yaitu menggabungkan gelombang $\mathrm{P}$ dan $\mathrm{S}$ yang dikenal sebagai Gelombang PS (converted-wave). Gelombang PS merupakan metode seismik ekplorasi yang menggunakan energi gelombang $P$ menjalar ke bawah dan direfleksikan ke atas sebagai gelombang S. Tujuannya untuk memanfaatkan properti gelombang $\mathrm{P}$ sebagai energi awal dan gelombang $\mathrm{S}$ 
sebagai energi yang di pantulkan, sehingga kekurangan dari gelombang $\mathrm{P}$ dapat ditutupi dengan adanya gelombang $S$.

Tujuan penelitian ini adalah untuk menganalisa perbandingan antara seismik sintetik PP dan PS berdasarkan pemodelan sumur. Pemodelan pada sumur yang akan dilakukan adalah Fluid Replacement Modeling (FRM) untuk melihat perubahan terhadap gelombang $P(V p)$, gelombang $S(V s)$ dan densitas ( $\rho)$. Kemudian perubahan fluida tersebut akan dianalisis respon terhadap seismik sintetik PP dan PS.

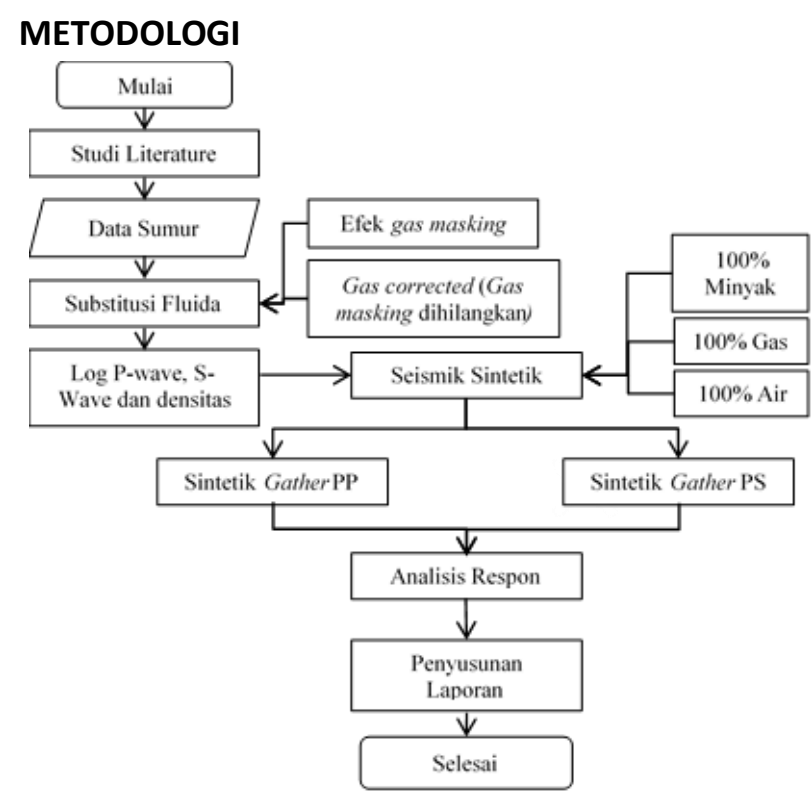

Gambar 1. Metodologi Pengerjaan.

\section{Pemodelan Substitusi Fluida}

Tahap ini bertujuan untuk mengganti fluida awal (in-situ) menjadi fluida lain (air, minyak dan gas). Hasil dari pemodelan substitusi fluida ini adalah log densitas, $\mathrm{Vp}$ dan Vs yang baru. Langkahlangkah pemodelan substitusi fluida (Gambar 2).

\section{Seismik Sintetik PP dan PS}

Pembuatan seismik sintetik menggunakan sintetik elastic wave berdasarkan komputasi full elastic wave. Sehingga mencakup multiples, converted wave, gelombang primer dan refraksi. Berikut langkah-langkah pembuatan sintetik seismik gather:
- Sebelum membuat sintetik gather, dibutuhkan wavelet untuk sintetik PP dan PS. Wavelet PP dan PS di dapat dari ekstraksi statistikal dari data seismik (Gambar 3).

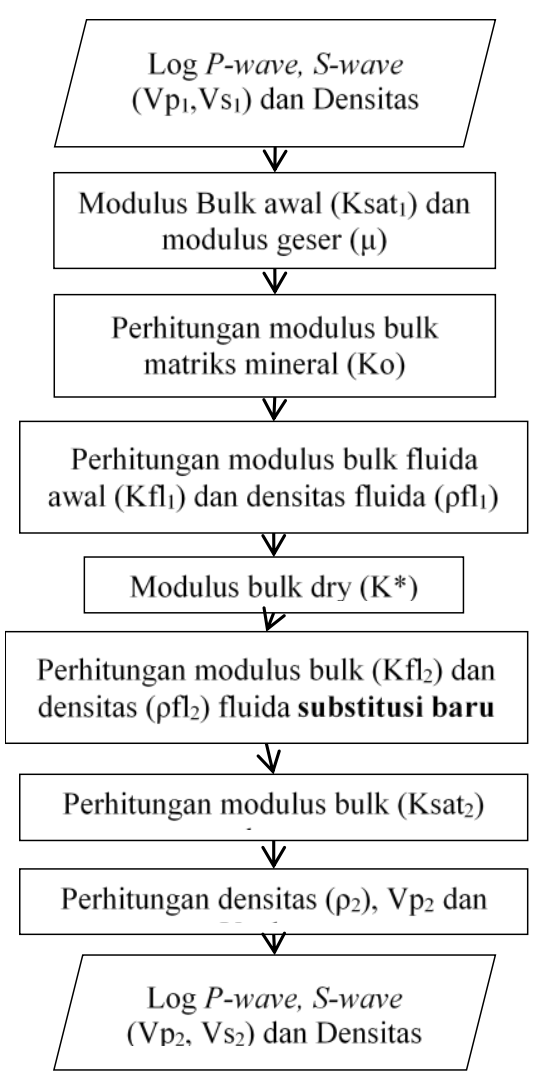

Gambar 2. Langkah Kerja Pemodelan Substitusi Fluida (Smith, 2003)

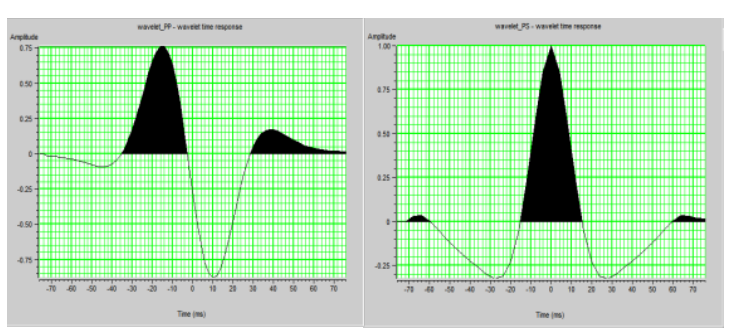

Gambar 3. Wavelet untuk Sintetik PP (Kiri), Sintetik PS (Kanan)

- Selanjutnya adalah penentuan parameterparameter dalam pembuatan sintetik seismik gather). Pemodelan pada sintetik PP menggunakan efek geometrical spreading, transmission loss ketika menjalar di bawah permukaan bumi. Kemudian, jumlah offset adalah 101 dengan minimum dan maksimum offset $0-4000 \mathrm{~m}$. Time window yang digunakan 
adalah sampai $6000 \mathrm{~ms}$ dengan sample rate 4ms.

- Respon berupa gelombang PP maka rekaman gelombang yang digunakan adalah komponen vertikal sedangkan ketika respon berupa gelombang PS dan gelombang PP digunakan horizontal komponen. Frekuensi sintetik gather adalah $0-125 \mathrm{~Hz}$. Setelah itu akan diproses pembuatan sintetik gather.

\section{HASIL DAN PEMBAHASAN}

\section{Analisis Pemodelan Substitusi Fluida}

Grafik hubungan antara Vp, Vs dan densitas terhadap perubahan saturasi fluida (Gambar 4, 5 dan 6) di kedalaman $1323.28 \mathrm{~m}$ dengan variasi perubahan saturasi air 0\%-100\%.

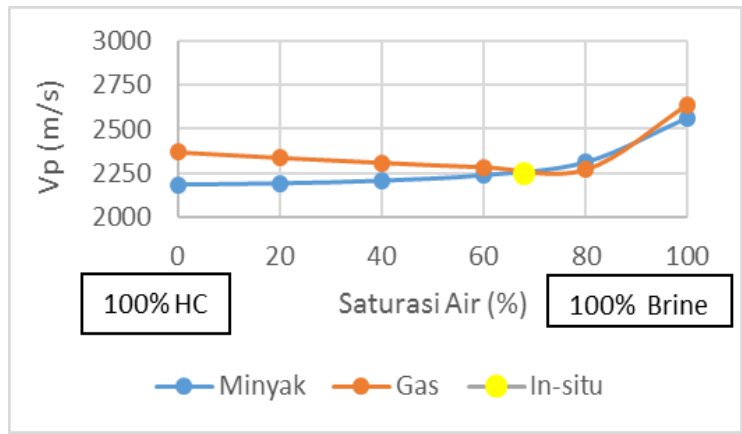

Gambar 4. Grafik Vp Terhadap Saturasi Air.

Kecepatan gelombang $\mathrm{P}(\mathrm{Vp})$ pada batuan terisi fluida gas lebih besar dibandingkan fluida minyak. Ini merupakan kasus yang jarang yang biasa terjadi pada gas sand (Smith, 2003). Ini Terjadi akibat penurunan densitas batuan yang drastis dan kenaikan modulus bulk saturasi ketika terisi gas. Bentuk grafik $V p$ terhadap saturasi air berbentuk polynomial sedangkan grafik Vs berbentuk linier (Gambar 5). Pada kasus gas, ketika saturasi air dinaikkan $0-80 \%$ kecepatan gelombang $\mathrm{P}$ menurun dan naik ketika saturasi air $80-100 \%$. Berbeda pada kasus minyak, kenaikan saturasi air 0-80\% berdampak pada kenaikan kecepatan gelombang $\mathrm{P}$ secara perlahan dan kenaikan secara signifikan pada saturasi air 80-100\% (Gambar 4).

$$
V p=\sqrt{\frac{K_{\text {sat }}+\frac{4}{3} \mu_{\text {sat }}}{\rho_{\text {sat }}}}
$$

Persamaan (1) menunjukkan bahwa hubungan densitas terhadap kecepatan gelombang $P$ tidak langsung melainkan ada pengaruh dari Ksat dan $\mu$ sat.

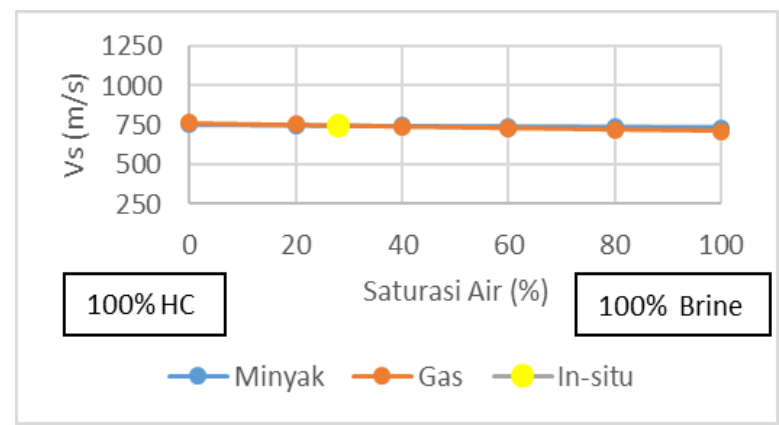

Gambar 5. Grafik Vs Terhadap Saturasi Air.

Perubahan kecepatan gelombang $\mathrm{S}$ tidak terlalu signifikan jika dibandingkan dengan perubahan gelombang $P$ terhadap saturasi air. Gambar 8 menunjukkan hubungan kecepatan berbanding terbalik terhadap kenaikan saturasi air. Kecepatan gelombang $\mathrm{S}$ pada fluida gas saat saturasi air 0\% lebih besar daripada fluida minyak. Ini disebabkan oleh pengaruh densitas gas yang lebih kecil dibandingkan minyak. Modulus geser batuan tidak dipengaruhi oleh saturasi fluida sehingga modulus batuan tersaturasi ( $\mu$ sat) sama dengan modulus batuan kerangka/ $d r y\left(\mu^{*}\right)$. Fluida tidak memiliki modulus geser sehingga nilainya 0 . Ketika disubstitusi dengan gas akan turun drastis dan menyebabkan nilai kecepatan gelombang $S$ meningkat (2).

$$
V s=\sqrt{\frac{\mu_{\text {sat }}}{\rho_{\text {sat }}}}
$$

Densitas batuan terisi fluida gas menunjukkan perubahan yang lebih besar dibandingkan fluida minyak, ditandai dengan kemiringan grafik (Gambar 6). Densitas batuan terisi gas lebih kecil dibandingkan minyak pada keadaan saturasi air 
garam 0\%. Perubahan densitas berbanding lurus dengan kenaikan saturasi air.

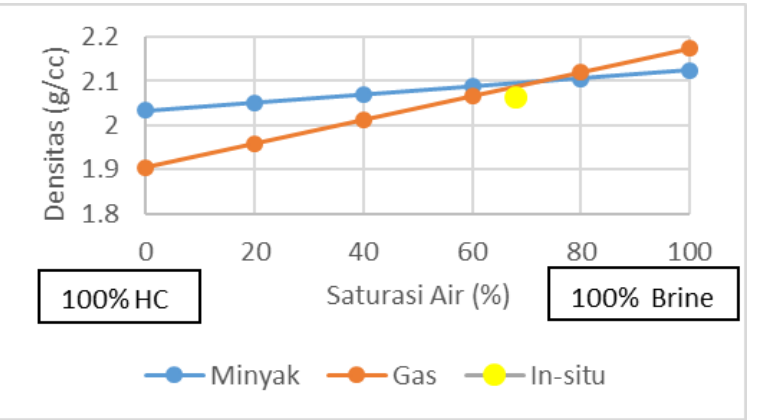

Gambar 6. Grafik Densitas Batuan Tersaturasi Terhadap Saturasi Air.

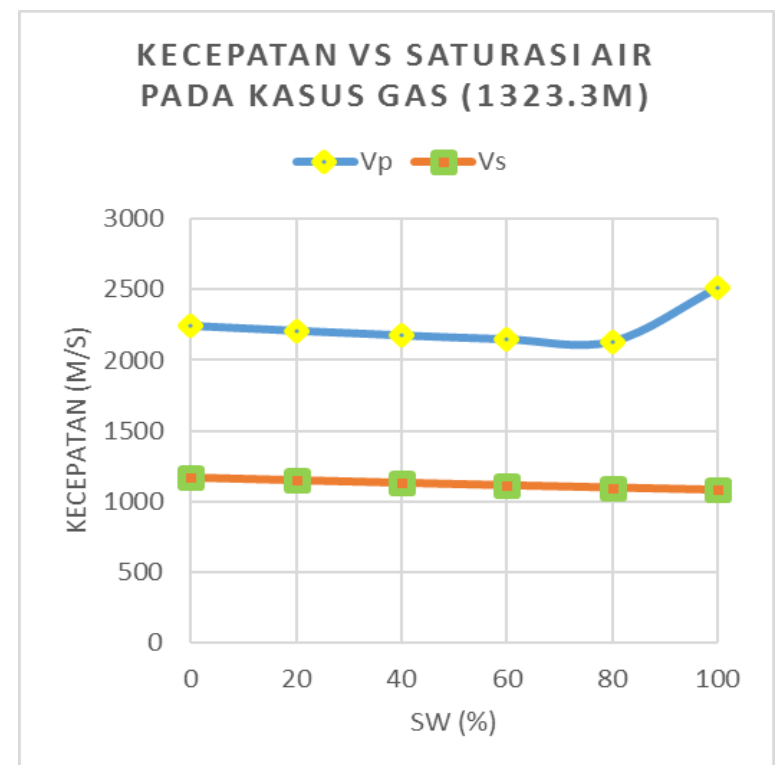

Gambar 7. Hubungan Kecepatan dengan Saturasi Air pada Kasus Gas di Kedalaman 1323.3m.

Kehadiran gas dan minyak pada batuan sangat berpengaruh terhadap kecepatan gelombang $P$ (Gambar 7 dan 8). Bentuk kurva kecepatan gelombang $\mathrm{P}$ pada kasus gas dan minyak terhadap bertambahnya saturasi air berbeda. Perhitungan kecepatan gelombang $\mathrm{P}$ dan $\mathrm{S}$ dilakukan pada kedalaman $1323 \mathrm{~m}$ dengan Porositas: 31.99\%, Kmatrix: $40 \mathrm{Gpa}, \mathrm{Kw}=2.38 \mathrm{Gpa}$, Kgas: $0.0185 \mathrm{Gpa}$, Koil: $0.0356 \mathrm{Gpa}$.

Bentuk kurva gelombang $\mathrm{P}$ pada kasus gas cenderung menurun seiring bertambahnya saturasi air pada 0\%-60\% kemudian pada saturasi air 60 $80 \%$ mulai naik dan naik secara drastis pada saturasi $80 \%-100 \%$. Bentuk kurva gelombang $\mathrm{P}$ pada kasus minyak cenderung naik perlahan saat saturasi air 0\%-60\% kemudian naik drastis pada saturasi air $80 \%-100 \%$.

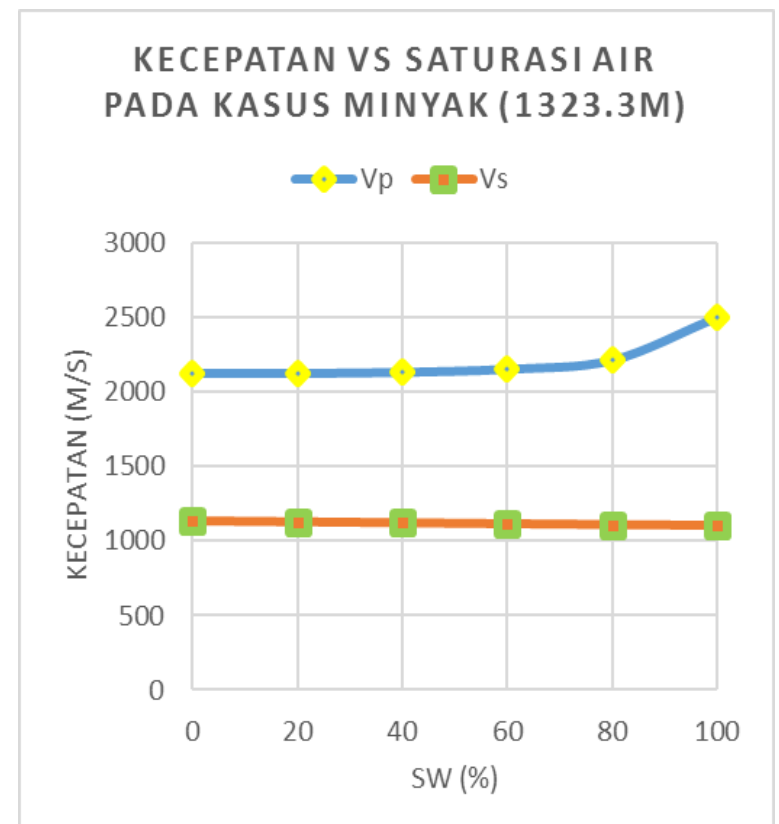

Gambar 8. Hubungan Kecepatan dengan Saturasi Air pada Kasus Minyak di Kedalaman 1323.3m.

\section{Analisis Perbandingan Respon Seismik PP dan PS}

Adanya efek gas pada log mengakibatkan respon seismik yang berbeda yaitu adanya perbedaan posisi waktu pada event yang sama. Posisi waktu log tanpa efek gas akan lebih cepat dari pada yang memiliki efek gas. Gambar 9 menunjukkan posisi event yang sama pada seismik yang memiliki efek gas (kiri) berada pada posisi waktu $500 \mathrm{~ms}$ sedangkan yang tidak memiliki efek gas berada pada posisi waktu $462 \mathrm{~ms}$. Keberadaan gas menunjukkan adanya time delay.

Frekuensi konten pada sintetik ditentukan oleh karakteristik wavelet yang digunakan pada proses sintetik. Ketika data sintetik PP ataupun PS di munculkan pada domain lain, maka spektrum data akan berubah (Hampson Russel, 2008). Ketika Sintetik PS di-display pada PP time maka data akan dikompres karena frekuensi yang muncul lebih tinggi daripada wavelet frekuensi (Gambar 10b). Ketika data sintetik PP di-display pada PS time maka data sintetik akan tertarik (stretch) dan frekuensi konten lebih rendah (Gambar 10a). 

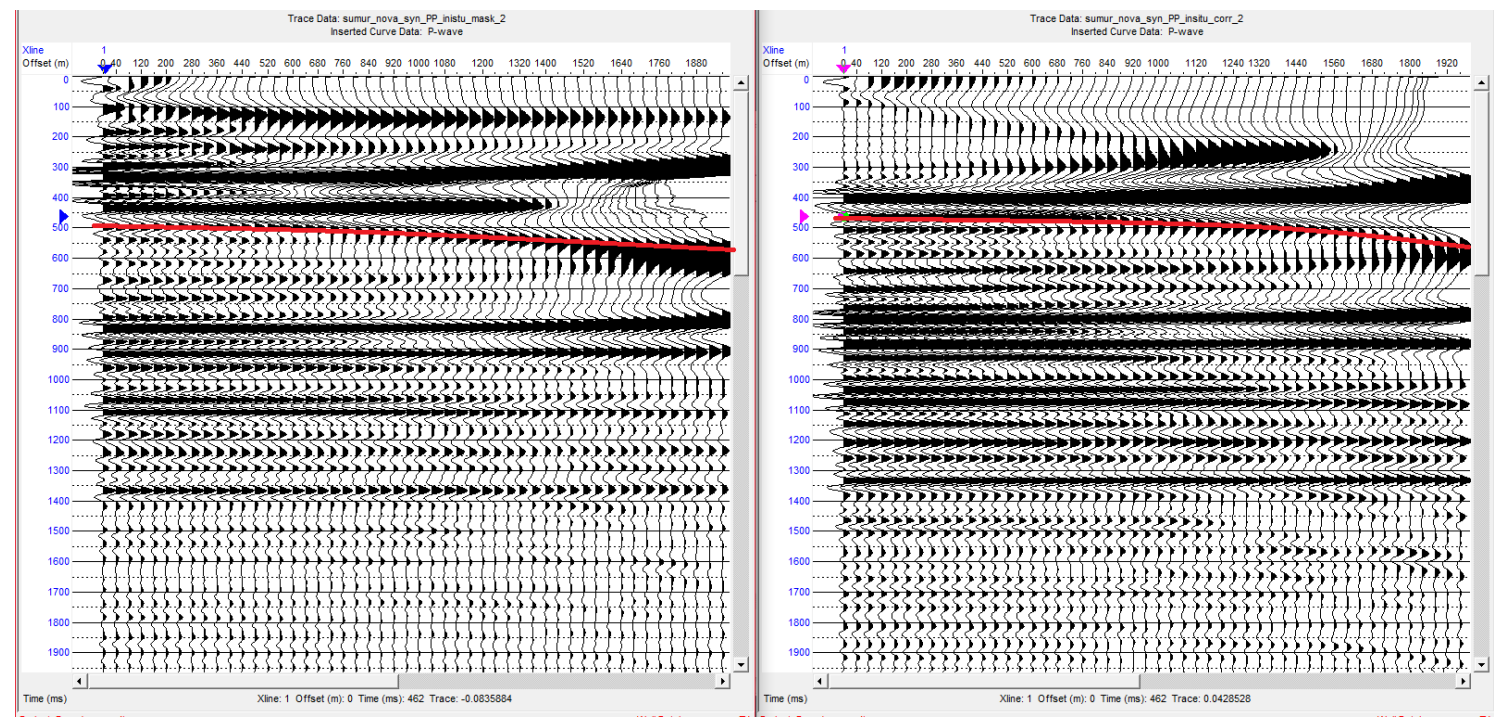

Gambar 9. Seismik Sintetik Gather PP dengan Efek Gas (Kiri), tanpa Efek Kas (Kanan).

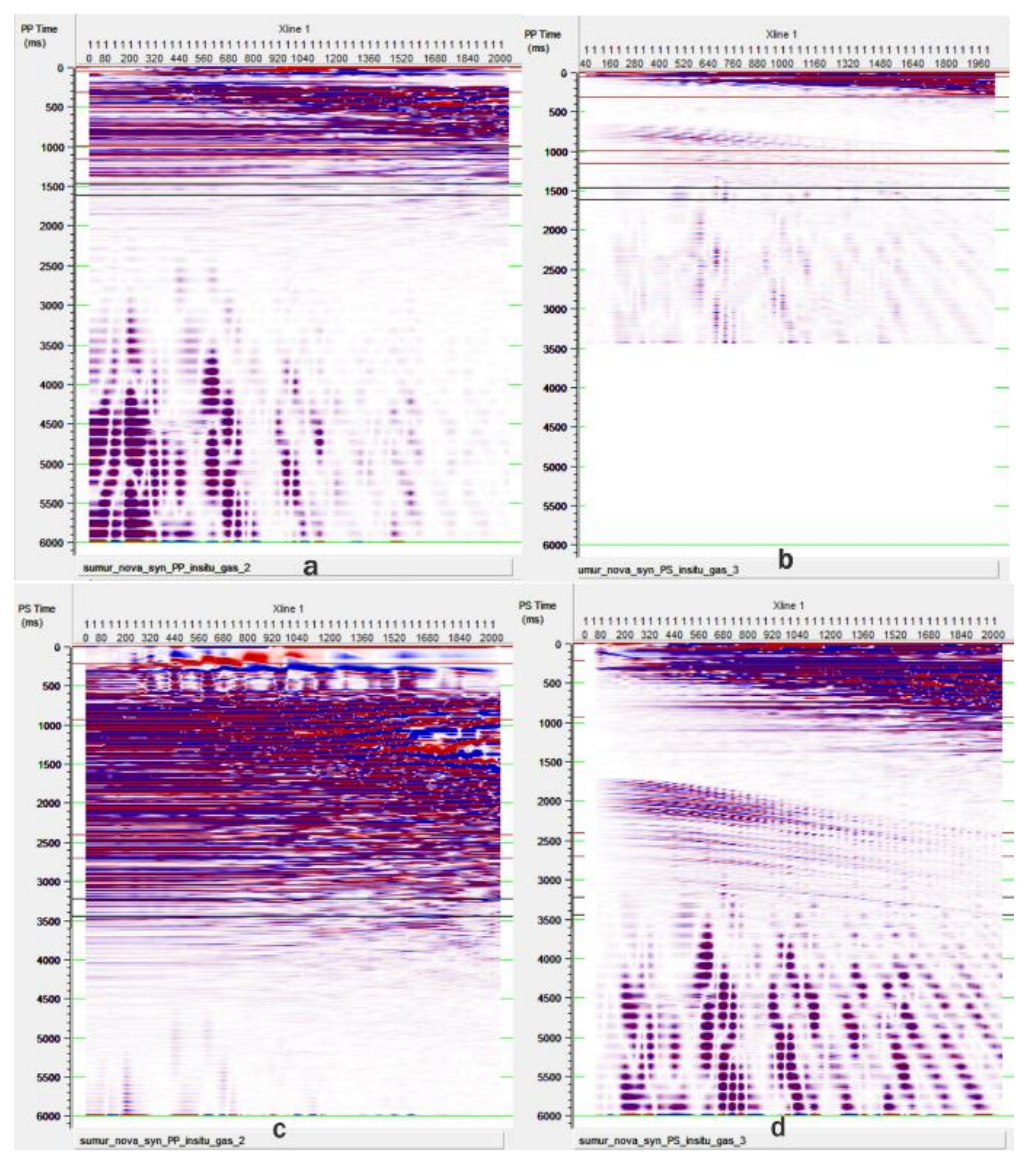

Gambar 10. Sintetik Gather Vertikal Komponen dan Horizontal pada PP Time (a) Komponen Vertikal (PP Data),

(b) Komponen Horizontal (PS Data) dan PS Time,

(c) Komponen Vertikal,

(d) Komponen Horizontal. 


\section{PENUTUP}

\section{Simpulan}

Berdasarkan penelitian yang telah dilakukan dapat diambil kesimpulan bahwa:

1. Perubahan properti batuan akibat fluida pengisi pori berpengaruh terhadap kecepatan gelombang $\mathrm{P}$ dan densitas (impedans batuan).

2. Kecepatan gelombang $S$ (Vs) ketika terisi gas akan lebih besar dibandingkan air dan minyak.

3. Kecepatan gelombang $P(\mathrm{Vp})$ naik ketika terisi fluida air dan gas dan turun ketika terisi minyak.

4. $V p$ batuan terisi gas lebih besar dibandingkan dengan minyak. Hal ini terjadi pada kasus reservoir gas sand.

5. Sintetik PS akan terkompres jika di-display pada domain waktu PP, sedangkan sintetik PP akan ter-strectch jika di-display pada domain PS

\section{Saran}

Saran dari penelitian ini adalah :

1. Pada penelitian selanjutnya, sebaiknya koreksi NMO menggunakan software pengolahan data (processing) seismik sehingga memberikan hasil penampang yang lebih baik.

2. Pada penelitian selanjutnya dapat dilakukan analisis AVO untuk melihat efek amplitude terhadap offset.

\section{Ucapan Terima Kasih}

Penulis mengucapkan terima kasih kepada para dosen pembimbing Dr. Ir. Amien Widodo, MS dan Firman Syaifuddin, S.Si., MT. atas ide penulisan dan pengarahannya selama proses penelitian hingga penulisan.

\section{DAFTAR PUSTAKA}

Hampson-Russel, 200., ProMC Well Modeling.

Smith, T. M., Sondergeld, C. H., \& Rai, C. S., 2003. Gassmann Fluid Substitution: A Tutorial. Geophysics, 68, h. 430-440.

Stewart, R. R., \& Lawton, D. C., 1996. P-S Seismic Exploration : A Mid-term Overview. CREWES Research Reports Volume 8, h. 1-34. 